\title{
Biology and feeding potential of Coccinella septempunctata (Linn.) against Lipaphis erysimi (Kalt) at different temperature regimes
}

\author{
Richa Varshney $^{*}$, R. R. Rachana ${ }^{1}$ and R. S. Bisht ${ }^{2}$ \\ ${ }^{1}$ Department of Insect Ecology, National Bureau of Agricultural Insect Resources, Bangalore-560024 (Karnataka), INDIA \\ ${ }^{2}$ Department of Entomology, Govind Ballabh Pant University of Agriculture \& Technology, Pantnagar-263145 \\ (Uttarakhand), INDIA \\ *Corresponding author. E-mail: richavarshney84@gmail.com
}

Received: January 13, 2016; Revised received: August 17, 2016; Accepted: October 3, 2016

\begin{abstract}
Biology and feeding potential of Coccinella septempunctata (Linn.) were studied in laboratory on $3^{\text {rd }}$ instar nymphs of mustard aphid (Lipaphis erysimi Kalt.) at two different temperature regimes. At $30 \pm 2^{0} \mathrm{C}$, fecundity, oviposition period, hatchability of eggs, male and female longevity $(232 \pm 70.46,12.8 \pm 3.91,82.87 \pm 6.66,22.70 \pm 2.21$ and $26.60 \pm 4.45$, respectively) were higher and incubation period, pre-oviposition period, total grub duration and pupal duration $\left(2.6 \pm 0.51,6.5 \pm 3.53,8.7 \pm 1.63\right.$ and $5.1 \pm 1.10$, respectively) were lesser in comparison to $25 \pm 2{ }^{\circ} \mathrm{C}$ where fecundity, oviposition period, hatchability of eggs, male and female longevity, incubation period, preoviposition period, total grub duration and pupal duration were 169.8 $\pm 61.12,7.9 \pm 1.37,71.68 \pm 4.08,16.2 \pm 1.31$ and $21.50 \pm 1.95,2.9 \pm 0.73,7.7 \pm 2.49,11.1 \pm 1.52$ and $5.8 \pm 0.918$, respectively . At $27 \pm 2{ }^{\circ} \mathrm{C}$, total mustard aphid consumption by a grub of $C$. septempunctata during the whole life span, was $424.4 \pm 2.78$ mustard aphids in comparison to $272.64 \pm 1.79$ mustard aphid at $23 \pm 2{ }^{\circ} \mathrm{C}$. Similarly an adult male and female consumed $103.2 \pm 1.52$ and 116.6 \pm 1.46 aphids per day respectively at $27 \pm 2{ }^{\circ} \mathrm{C}$ in comparison to $65.6 \pm 1.02$ and $71.8 \pm 1.60$ at $23 \pm 2^{\circ} \mathrm{C}$. Thus, at both temperatures aphid consumption increased gradually till $4^{\text {th }}$ instar and $30 \pm 2^{\circ} \mathrm{C}$ was found to be most suitable temperature as compared to $25 \pm 2^{0} \mathrm{C}$ for the life history of $C$. septempunctata. Hence, it could be concluded that $C$. septempunctata might play a suitable role in biointensive Integrated Pest Management programme because of better longevity and high predatory potential against the mustard aphid.
\end{abstract}

Keywords: Biology and feeding potential, Coccinella septempunctata, Lipaphis erysimi, Rapeseed-mustard

\section{INTRODUCTION}

Rapeseed-mustard, Brassica juncea (Linnaeus) is one of the important cruciferous oilseed crops cultivated all over India but its yield is largely affected by number of insect pests. Among all the insect pests, the mustard aphid, Lipaphis erysimi (Kaltenbach) (Homoptera: Aphididae) has gained the status of key pest of rapeseed-mustard in India. It feeds by sucking sap from its host and damage to the crop ranging from 9 to $96 \%$ in different agroclimatic conditions of India (Singh and Sharma, 2002; Singh and Sachan, 1994; Singh and Sachan, 1995; Parmar et al., 2007). Among all the natural enemies, aphidophagous coccinellids especially Coccinella septempunctata is well known potential aphid predator and manage the pest in field (Bilashini and Singh, 2009 Sethi and Atwal, 1964) in mustard ecosystem. Both grub and adults feed voraciously on mustard aphid but their feeding efficiency varies from stage to stage and at different temperatures. For the effective use of predaceous coccinellids in the integrated pest management programme, a complete investigation on their bio-ecology and predation potential are of utmost importance. The knowledge of biology plays an important role in mass production and its utilization in pest management programme. It is quite evident that temperature has a great impact on biology of this predator. To insight the information on description, duration of different stages of $C$. septempunctata and its feeding propensity on mustard aphid at different temperature, the present study was undertaken in the Laboratory, GBPUA\&T, Pantnagar. Being a predator, the knowledge of its biotic potential is helpful in formulating the strategy of biological control of insect pests. Keeping in view the importance of $C$. septempunctata as a biological control agent, the present study was carried out to gather relevant information with particular reference to biology and devouring propensity of this coccinellid at two different temperatures on rapeseed-mustard aphid in the laboratory.

\section{MATERIALS AND METHODS}

Maintenance of stock culture of $\boldsymbol{C}$. septempunctata: The initial culture of $C$. septempuncata was raised by collecting the males and female from the mustard field at Crop Research Center, Pantnagar and reared in the laboratory at $25 \pm 1{ }^{\circ} \mathrm{C}$ and relative humidity $65 \pm 5 \%$ on mustard aphid in the specimen jars $(20 \times 15 \mathrm{~cm})$ dur- 
ing the Rabi cropping seasons. Fresh leaves and twigs of mustard harboured with L.erysimi were placed inside each jar to provide food to the beetles. The jars were covered with the muslin cloth fastened with rubber bands. The part of the host plants (i.e. leaves/ twigs/ inflorescence etc) with the deposited eggs were kept in separate jars till they become adults.

Life history of $C$. septempunctata Linn. on L. erysimi in laboratory at different temperature regimes: The biology of $C$. septempunctata was studied in the laboratory at $30 \pm 2^{\circ} \mathrm{C}$ and $25 \pm 2^{\circ} \mathrm{C}$ and $\mathrm{RH} 70 \pm 5 \%$ on L. erysimi, on mustard. The males and females were collected from this stock culture and kept separately in petri dishes $(15 \mathrm{~cm}$ dia) for mating. The mated females individually were allowed to oviposit in separate petridishes $(15 \mathrm{~cm} \mathrm{dia})$ containing mustard aphid. These petridishes were then kept inside the B.O.D. incubators at two different temperatures viz. $30 \pm 2^{\circ} \mathrm{C}$ and $25 \pm 2^{\circ} \mathrm{C}$ separately to observe incubation period, hatching and successive life history stages of the predator.

The freshly hatched tiny grubs were reared individually in petridishes after providing sufficient food (i.e. first instar nymphs of mustard aphid) to them under 10 replications at two different temperatures viz. $30 \pm 2^{\circ} \mathrm{C}$ and $25 \pm 2^{\circ} \mathrm{C}$. The duration of different larval instars and pupal period was recorded separately in each replication. After adult emergence, 10 pairs of beetle were released separately in jars $(15 \times 10 \mathrm{~cm})$ to observe preoviposition, oviposition and post-oviposition periods under ten replications. The number of eggs laid by each female during her life time was also observed. The adult longevity of male and female was also worked out.

Feeding propensity of grubs and adult of $C$. septempunctata on $L$. erysimi, the mustard aphid: Total feeding potential of grub and newly emerged adult of C. septempunctata, on $3^{\text {rd }}$ instar nymphs of mustard aphid $(L$. erysimi, Kalt.) was observed in the laboratory right from the first instar upto $4^{\text {th }}$ instar and then newly emerged adult for five consecutive days. The experiments were conducted in $100 \times 17 \mathrm{~mm}$ glass petriplates, at two different temperature regimes viz. $27 \pm 2^{\circ} \mathrm{C}$ and $23 \pm 2^{\circ} \mathrm{C}$ and relative humidity of $65 \pm 5 \%$ respectively. Feeding experiments were replicated five times and in each replication single grub/ adult of predator was released. To start with the experiment the grubs and adults were kept starved for 24 hours except the first instar grubs. In each replication, 150 third instar nymphs of mustard aphid were released gently on fresh foliage of mustard with the help of soft camel hair brush ( 0 number). The experiment was run for 24 hours, thereafter the number of unconsumed aphids left over in petri dishes was counted. The actual number of aphids consumed by grubs/adult per $24 \mathrm{hrs}$ was calculated.

\section{RESULTS AND DISCUSSION}

Feeding potential of grubs and adults of $C$. septempunctata on L. erysimi in laboratory: It was evident from the present study (Table 1) that first, second, third and fourth instar larva of $C$. septempunctata consumed on an average of $15.86 \pm 0.34,45.1 \pm 0.45,124.62 \pm$ 0.88 and $238.82 \pm 1.11$ aphids respectively at $27 \pm 2^{0} \mathrm{C}$ and $65 \pm 5$ percent respectively in a total larval period of 9-10 days. During the total larval period the grub consumed on an average of $424.4 \pm 2.78$ mustard aphid and the newly emerged adult male consumed on an average of 103.2 \pm 1.52 aphids per day as compared to the newly emerged adult female which consumed on an average of $116.6 \pm 1.46$ aphids per day when fed on mustard aphid for 5 consecutive days at similar stress of ecological conditions. However, this result is in contrast to the findings of Gour and Pareek (2003) who reported an average consumption of 612.91 to 613.56 aphids during a complete larval period. Similarly at $23 \pm 2^{\circ} \mathrm{C}$ and $65 \pm 5$ percent relative humidity, first, second, third and fourth instar grub of the predator consumed on average of $19.3 \pm 0.29,24.38 \pm 0.31,53.16 \pm 0.5$ and $175.8 \pm 0.69$ aphids respectively in a total larval period of 10 11 days ) During the total larval period, the grub consumed on an average of $272.64 \pm 1.79$ mustard aphids. Newly emerged male and female on the other hand consumed $65.6 \pm$ 1.02and $71.8 \pm 1.60$ aphids per day respectively when fed on mustard aphid for 5 consecutive days under similar stress of ecological conditions. Per day aphid consumption by grub during larval period at both the temperatures is evident from Figure 1. This result is in close approximation with Gautam (2002) who observed that the grubs of $C$. septempunctata consumed 281 aphids during its larval period and Singh and Singh (2014) who reported total aphid consumption by grub was 212 aphids. Higher aphid consumption by the female as compared to male $C$. septempunctata has also been reported by Gour and Pareek (2003).

Life history of $C$. septempunctata on mustard aphid, $L$. erysimi at $30 \pm 2{ }^{0} \mathrm{C}$ : At a temperature of $30 \pm 2^{\circ} \mathrm{C}$ and $70 \pm 5 \%$ relative humidity, $C$. septempunctata laid on an average of $232 \pm 5.45$ eggs in its total life span (Table 2). The eggs were cigar-shaped, shining deep yellow in colour and lay in clusters mostly on the under surface of leaves. The incubation period was $2.6 \pm 0.51$ days and an average $82.87 \pm 6.66 \%$ hatchability was observed. This finding is in close conformity with Mishra et al. (2005) who observed the incubation period of 3 days with $86.6 \%$ hatchability at $28 \pm 2{ }^{\circ} \mathrm{C}$. The average pre-oviposition, oviposition and post-oviposition period of C. septempunctatawas $6.5 \pm 3.53,12.8 \pm 3.91$ and $3.2 \pm 1.31$ days respectively (Table 2). These results are in corroboration with those of Behera et al. (1999), Petro and Behera, (2005), Singh et al. (2009) and Singh and Singh (2014). The average duration of first, second, third and fourth instar larvae was $1.6 \pm 0.69,1.7 \pm 0.48,2.3 \pm 0.67$ and $3.1 \pm 0.87$ days respectively. The total larval period ranged from 7-12 days whereas the pupal period varied from 4-7 days. Agarwala and Saha (1986), Behera et al. (1999) reported 12.6 and 9.35 days grub period of $C$. septempunctata on aphids. The longevity of male beetle ranged from 19-26 days while the female adult beetle survived for 21-33 days (Table 2). 
Table 1. Feeding potential of grubs and adults of C. septempunctata on L. erysimi at two different temperature regimes.

\begin{tabular}{|c|c|c|}
\hline Instar/adult & $23 \pm 2^{0} \mathrm{C}, 65 \pm 5 \% \mathrm{RH}$ & $27 \pm 2^{0} \mathrm{C}, 65 \pm 5 \% \mathrm{RH}$ \\
\hline & Average consumption of aphids instar & Total consumption of aphids /instar \\
\hline $1^{\text {st }}$ instar grub & $19.3 \pm 0.29$ & $15.86 \pm 0.34$ \\
\hline $2^{\text {nd }}$ instar grub & $24.38 \pm 0.31$ & $45.1 \pm 0.45$ \\
\hline $3^{\text {rd }}$ instar grub & $53.16 \pm 0.5$ & $124.62 \pm 0.88$ \\
\hline $4^{\text {th }}$ instar grub & $175.8 \pm 0.69$ & $238.82 \pm 1.11$ \\
\hline $\begin{array}{l}\text { Total no. of aphids consumed during } \\
\text { larval development }\end{array}$ & $272.64 \pm 1.79$ & $424.4 \pm 2.78$ \\
\hline $\begin{array}{l}\text { Average consumption of aphid/Adult } \\
\text { male/day }\end{array}$ & $65.6 \pm 1.02$ & $103.2 \pm 1.52$ \\
\hline $\begin{array}{l}\text { Average consumption of aphid/Adult } \\
\text { female/day }\end{array}$ & $71.8 \pm 1.60$ & $116.6 \pm 1.46$ \\
\hline
\end{tabular}

Table 2. Biological parameters of C. septempunctata on mustard aphid, L. erysimi at two different temperatures.

\begin{tabular}{lllll}
\hline Biological parameter & \multicolumn{2}{l}{ At $\mathbf{3 0} \pm \mathbf{2}^{\mathbf{0}} \mathbf{C}$ and $\mathbf{7 0} \pm \mathbf{5 \%} \mathbf{R H}$} & \multicolumn{2}{c}{ At $\mathbf{2 5} \pm \mathbf{2}^{\mathbf{0}} \mathbf{C}$ and $\mathbf{7 0} \pm \mathbf{5 \%} \mathbf{R H}$} \\
\cline { 2 - 5 } & Mean \pm SEM & Range & Mean \pm SEM & Range \\
\hline Incubation period (in days) & $2.6 \pm 0.51$ & $2-3$ & $2.9 \pm 0.73$ & $2-4$ \\
Larval instars (in days) & $1.6 \pm 0.69$ & $1-3$ & $3.1 \pm 0.87$ & $2-4$ \\
$1^{\text {st }}$ instar & $1.7 \pm 0.48$ & $1-2$ & $2.2 \pm 0.78$ & $1-3$ \\
$2^{\text {nd }}$ instar & $2.3 \pm 0.67$ & $1-3$ & $2.1 \pm 0.87$ & $1-3$ \\
$3^{\text {rd }}$ instar & $3.1 \pm 0.87$ & $2-4$ & $3.3 \pm 0.94$ & $2-5$ \\
$4^{\text {th }}$ instar & & & & $10-13$ \\
Total grub period (in days) & $8.7 \pm 1.63$ & $7-12$ & $11.1 \pm 1.52$ & $4-7$ \\
Pupal period (in days) & $5.1 \pm 1.10$ & $4-7$ & $5.8 \pm 0.918$ & $14-18$ \\
Longevity male (in days) & $22.70 \pm 2.21$ & $19-26$ & $16.2 \pm 1.31$ & $18-24$ \\
Longevity female (in days) & $26.60 \pm 4.45$ & $21-33$ & $21.50 \pm 1.95$ & $98-218$ \\
Fecundity/female (no.) & $232 \pm 5.45$ & $103-267$ & $169.8 \pm 6.78$ & $65.9-78.32$ \\
\% Hatchability & $82.87 \pm 6.66$ & $73.8-94.4$ & $71.68 \pm 4.08$ & $4-11$ \\
Pre-oviposition period(in days) & $6.5 \pm 3.53$ & $3-12$ & $7.7 \pm 2.49$ & $6-10$ \\
Oviposition period(in days) & $12.8 \pm 3.91$ & $8-21$ & $7.9 \pm 1.37$ & $2-6$ \\
Post-oviposition period (in days) & $3.2 \pm 1.31$ & $2-6$ & $3.9 \pm 1.59$ & \\
\hline
\end{tabular}

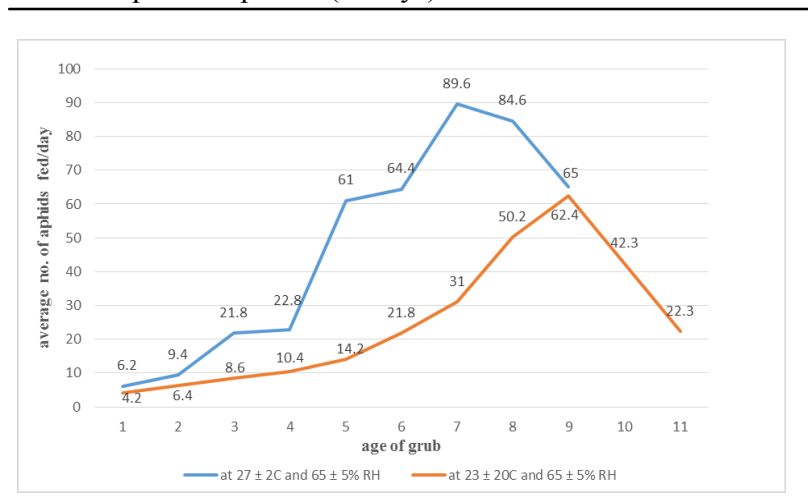

Fig. 1. Feeding potential of C. septempunctata grub on mustard aphid, L.erysimi at two different temperatures.

Life history of $C$. septempunctata on mustard aphid, $L$. erysimi at $25 \pm 2{ }^{\circ} \mathrm{C}$ : Considering the biology of $C$. septempunctata at a temperature of $25 \pm 2^{0} \mathrm{C}$ and $70 \pm 5 \%$ relative humidity it was revealed from Table 2 that the female laid on an average of $169.8 \pm 6.78$ eggs in its total life span. The incubation period ranged from 2-4 days and average hatchability of $71.68 \pm 4.08 \%$ was recorded. The average pre-oviposition period, oviposition period and post oviposition period were $7.7 \pm 2.49,7.9 \pm 1.37$ and $3.9 \pm 1.59$ days respectively. The average duration of larval instars was $11.1 \pm 1.52$ days. Singh and Singh (2014) also reported average grub duration is 11.15 days on aphid. Average pupal period was $5.8 \pm 0.91$ days. The adult male and female survived for 14-18 days and 18-24 days respectively. A more or less similar results were obtained by Khurseed et al. (2006) who reported that adult male and female beetles survived for $15.24 \pm 8.10$ days and $20.18 \pm .41$ days respectively.

These findings are supported by Srivastava (2003) who noticed that the developmental period of this predator was shortest $\left(11.7 \pm 0.09\right.$ days) at $35^{\circ} \mathrm{C}$ and longest $(20.6 \pm 0.35$ days) at $20^{\circ} \mathrm{C}$.

\section{Conclusion}

Thus present findings support temperature $30 \pm 2^{\circ} \mathrm{C}$ is suitable for $C$. septempunctata development as oviposition period, hatchability of eggs, fecundity and male and female longevity was higher at this temperature. Similarly, it was also revealed that at both temperatures, $\left(23 \pm 2^{\circ} \mathrm{C}\right.$ and $27 \pm 2^{\circ} \mathrm{C}$ ) as the instar/age of grubs increased, the predation rate also increased tangibly and higher feeding propensity of newly emerged female in comparison to male was also evident. Thus it could be concluded that due to high fecundity, longevity and predatory potential, it might play a suitable role in biointensive Integrated Pest Management programmes. 


\section{ACKNOWLEDGEMENTS}

The authors are highly thankful to the Head of Department Entomology, GBPUA\&T, Pantnagar, for providing laboratory facilities.

\section{REFERENCES}

Agarwala BK, Saha JL (1986). Larval voracity, development and relative abundance of predators of Aphis gossypii on cotton in India, pp. 339-344. In: Ecology of Aphidophaga (ed. Hodek, I.), Academia, Prague and Dr. W. Junk, Dordrecht.

Behera MK, Behera R, Patro B (1999). Biology and feeding potential of Coccinella septempunctata Linnaeus (Coleoptera: Coccinellidae) on the chrysanthemum aphid, Macrosiphoniella sanborni (Gillette). J. Biol. Control, 13:39-43

Bilashini Y, Singh TK (2009). Studies on population dynamics and feeding potential of Coccinella septempunctata Linnaeus in relation to Lipaphis erysimi (Kaltenbach) on cabbage. Indian J. Appl. Entomol, 23 (2):99-103

Gautam, R.D.; Subhash, Chander; Sharma, V.K.; Jagdish, Ram and Singh, Ram. (2002). Feeding potential and preference of larval Coccinella septempunctata Linn. preying on aphids. Annals of Agricultural Research, 23 (1): $1-3$

Gour, I.S. and Pareek, B.L. (2003). Biology and predation potential of Coccinella septempunctata Linnaeus on mustard aphid, Lipaphis erysimi (Kalt.) in Semi-Arid region of Rajasthan. Annals of Biology Hissar, 19 (2): 225-229

Khursheed, R.; Barkat, Hussain; Ahmad, S.B. and Ashraf, M. (2006). Biology and feeding potential of Coccinella septumpunctata on mustard aphid, Lipaphis erysimi. International Journal of Zoological Research, 2(1): 30- 33

Mishra, S.K.; Kanwat, P.M. and Singh, S.P. (2005). Bionom- ics of Coccinella septempunctata Linn. (Coccinellidae: Coleoptera), a potential predator of mustard aphid. $A n$ nals of Agricultural Research, 26 (3): 453-457

Parmar, G.M.; Kapadiia, M.N.; Jadav, N.B. and Zizala, V.J. (2007). Avoidable losses due to Lipaphis erysimi (Kalt.) in mustard. Asian journal of Bioscience, 2 (1/2): 73-75

Petro D, Behera MK (2005). Biology and feeding potential of some aphidophagous coccinellids (Coleoptera: Coccinellidae) in Orissa. J. Aphidol, 19:101-107

Sethi, S.L. and Atwal, A.S. (1964). Influence of temperature and humidity on the development of different stages of Coccinella septempunctata Linn. Indian J. Agril. Sci., 34: $166-171$

Singh YP, Meghwal HP, Singh SP, Sharma KC (2009). Biology and feeding potential of Coccinella septempunctata Linnaeus on the mustard aphid, Lipaphis erysimi Kaltenbach. Indian J. Entomol, 71(30):196-198

Singh, C.P. and Sachan, G.C. (1994). Assessment of yield losses in yellow sarson due to mustard aphid, Lipaphis erysimi kalt. Journal of Oilseed Research, 11(2): 179-184

Singh, C.P. and Sachan, G.C.(1995). Estimation of losses in yield rapeseed. Brassica campestris by the mustard aphid, Lipaphis erysimiKalt. In Tarai, India. Insect science and its application, 16: 283-286

Singh, Y.P. and Sharma, K.C. (2002). Integrated approach to manage the mustard aphid Lipaphis erysimi (Kaltenbach) (Homoptera :Aphididae) in oilseed Brassica crops- a review. Journal of Amphibiology, 16: 77-78

Srivastava, Shefali. (2003). Influence of temperature on certain biological attributes of a ladybeetle Coccinella septempunctata Linnaeus. Entomologia Sinica, 10(3): 185-193

Singh Kuldeep and Singh NN (2014). Biology and devouring propensity of lady bird beetle, Coccinella septempunctata Linnaeus on rapeseed mustard aphid, Lipaphis erysimi Kaltenbach. African Journal of Agricultural Research, 9 (1): 61-64 